\title{
LA DESPARLAMENTARIZACIÓN DEL SISTEMA POLÍTICO ESPAÑOL. DE PARLAMENTARISMO EXCESIVAMENTE RACIONALIZADO A UN PARLAMENTO DILUIDO
}

ESPERANZA GÓMEZ CORONA

N.o 111, mayo-agosto 2021 
SUMARIO

I. PLANTEAMIENTO. II. LA POSICIÓN DE LAS CORTES GENERALES EN EL SISTEMA PARLAMENTARIO ESPAÑOL. UN BREVE APUNTE SOBRE UN MODELO EXCESIVAMENTE RACIONALIZADO. III. LA ACTIVIDAD PARLAMENTARIA EN EL PERÍODO 2011-2015: UN PARLAMENTO DILUIDO.1. La investidura de la presidencia del gobierno como primera misión parlamentaria. 2. El fin del principio de anualidad presupuestaria. 3. El Parlamento que no legisla. 4. La banalización del control de la acción del gobierno. 5. Una misión casi imposible: la designación parlamentaria. IV. A MODO DE REFLEXIÓN. LA DESPARLAMENTARIZACION DEL SISTEMA POLÍTICO ESPAÑOL. 


\title{
LA DESPARLAMENTARIZACIÓN DEL SISTEMA POLÍTICO ESPAÑOL. DE PARLAMENTARISMO EXCESIVAMENTE RACIONALIZADO A UN PARLAMENTO DILUIDO
}

\author{
ESPERANZA GÓMEZ CORONA \\ Profesora Titular de Derecho Constitucional \\ Universidad de Sevilla ${ }^{1}$
}

\section{PLANTEAMIENTO}

El sistema parlamentario que dibuja el constituyente de 1978 sitúa a las Cortes Generales en el centro de la vida política española, convirtiéndolas en el único órgano que goza de legitimidad democrática directa y tiene atribuida las más importantes funciones constitucionales: la actualización de la voluntad constituyente mediante la potestad legislativa, la aprobación de las cuentas anuales y el control de la acción del gobierno. Pero antes que todo ello y como primera misión constitucional, el Congreso de los Diputados tiene la responsabilidad de investir a la persona titular de la presidencia del gobierno.

No sólo eso. Su legitimidad democrática directa hace que participe de la elección de miembros de importantes órganos constitucionales como el Tribunal Constitucional, el Consejo General del Poder Judicial o el Defensor del Pueblo, necesarios para que todo el engranaje de nuestro sistema constitucional funcione adecuadamente.

En los últimos años sin embargo, estamos asistiendo a una situación en la que el Parlamento no cumple con normalidad ninguna de sus misiones constitucionales, con el menoscabo que eso supone para el sistema democrático en su conjunto.

Esperanza Gómez Corona. Departamento de Derecho Constitucional. Facultad de Derecho. Universidad de Sevilla. C/ Enramadilla 18-20.41071 Sevilla. España. Email: gcorena@us.es

(C) UNED. Revista de Derecho Politico 
Como señalara García Pelayo, el Derecho «no es la pura norma sino la síntesis de la tensión entre la norma y la realidad con que se enfrenta» ${ }^{2}$ y la realidad del Parlamento en los últimos años ha cambiado sustancialmente, incidiendo en la calidad y funcionalidad de nuestro sistema de gobierno.

\section{LA POSICIÓN DE LAS CORTES GENERALES EN EL SISTEMA PARLAMENTARIO ESPAÑOL. UN BREVE APUNTE SOBRE UN MODELO EXCESIVAMENTE RACIONALIZADO}

Nuestra Constitución opta de manera clara por un sistema parlamentario de gobierno racionalizado, que refuerza la posición del Ejecutivo frente a las Cortes Generales, a pesar de que son estas últimas las depositarias de la voluntad general. En esta decisión pesaron tanto las experiencias propias ${ }^{3}$, como las vividas en el continente europeo $^{4}$, que acabaron influyendo de manera decisiva en los redactores de la Constitución.

En el origen de este diseño late una preocupación compartida por la estabilidad y la eficacia gubernamental, en cuyo origen se encuentra lo que Fernández-Miranda Campoamor ha calificado de los dos fantasmas de la Transición: «el fantasma de la fragmentación de las Cámaras y el fantasma de la atomización, debilidad e inconsistencia de los partidos políticos» ${ }^{5}$. En un momento tan delicado preocupa mucho que los gobiernos surgidos tras las elecciones no fueran capaces de afrontar los cambios necesarios para consolidar la incipiente democracia española. De ahí, que se optara

2 García Pelayo, M., Derecho Constitucional Comparado, 2a edición, Manuales de la Revista de Occidente, Madrid, pág. 20.

3 Como ha destacado Aranda Álvarez, «la Constitución ha diseñado un parlamentarismo racionalizado de Primer Ministro que, teniendo en cuenta las funestas experiencias de los modelos de parlamentarismo asambleario del Siglo XIX y primeras décadas del XX, se muestra como una opción equilibrada y constitucionalmente inteligente. Sin embargo, la práctica de muchos de esos recursos del sistema, puesta en manos de un modelo de partidos excesivamente dominadores de la acción política, ha llevado a un resultado altamente criticable por lo que tiene de inversión del protagonismo que corresponde a cada uno de los dos poderes en liza». Aranda Álvarez, E., «El sistema parlamentario de la Constitución Española de 1978», Cuarenta años de Constitución, http://idpbarcelona.net/sistema-parlamentario-la-constitucion-espanola-1978/2019, 4 de febrero de 2019, p 1.

4 «De todo ese movimiento revisionista europeo son dos los logros en que van a inspirarse nuestros constituyentes (y no sólo los pertenecientes a partidos mayoritarios): conseguir un gobierno fuerte y estable y un parlamento regulado, controlado por los partidos, para procurar las más altas cotas de gobernabilidad posible». Paniagua Soto, J.L., «Sobre la forma de gobierno parlamentario en España: un parlamentarismo racionalizado de corte presidencial», en Seminario Internacional sobre el parlamentarismo europeo y el presidencialismo norteamericano cara a cara, Fundación Manuel Giménez Abad de Estudios Parlamentarios y del Estado Autonómico, 2020, pp. 4 y 5.

5 Fernández-Miranda Campoamor, A., «Sobre la forma de gobierno: ¿un exceso de racionalización?», en García Roca, F.J. y Alberti Rovira, E. (coords), Treinta años de Constitución, Tirant lo Blanch, 2020, p. 855 . 
por un sistema electoral proporcional corregido, para no fomentar una excesiva fragmentación de las Cámaras y por un sistema parlamentario de gobierno racionalizado, con mecanismos para fortalecer al Ejecutivo en un momento clave.

En este contexto, el sistema parlamentario de gobierno se adereza de elementos destinados a dotar de estabilidad al gobierno y a convertir el Parlamento en un mero ratificador de las políticas gubernamentales, que necesitan su intervención formal para poder ser puestas en práctica. Y ello se hace con medidas de tres tipos: electorales en primer lugar, de organización y procedimiento interno de las Cámaras parlamentarias en segundo y, por último, de legitimación del gobierno y reforzamiento de la figura de la presiden$c i{ }^{6}$. Hasta tal punto es así que en la doctrina ha habido quien ha llegado a hablar de Parlamento frenado 7 .

Con respecto a las medidas de corte electoral, están ya presentes en el diseño previsto en el Decreto-ley de Medidas Electorales de 1977, que rigió la elección a las Cortes que acabarían siendo constituyentes para pasar luego a la misma Constitución, cuya regulación sería completada en la LOREG. El modelo funciona en la práctica como proporcional con un importante sesgo mayoritario ${ }^{8}$, provocando una significativa reducción de la complejidad manifestada en las urnas. Ciertamente, la combinación del sistema D’Hondt con la provincia como circunscripción electoral que además cuenta con un mínimo de escaños asignados por la Constitución y fijados en 2 por la ley electoral, unido al número relativamente bajo de miembros del Congreso, provoca efectos sobre la representación parlamentaria, incrementando de manera notable la representación de la primera y segunda fuerza en cada circunscripción. El sistema es completado con una barrera electoral del 3 por ciento, inaplicable en la gran mayoría de las circunscripciones dado que el sistema impide la atribución de escaños a las fuerzas que han obtenido menos del 3 por ciento. De esta manera, el sistema electoral fomenta la concentración de voto, impulsa el voto útil y durante mucho tiempo ha reducido la complejidad abriendo la dinámica hacia un bipartidismo sólo limitado por la representación nacionalista en algunas zonas del territorio?.

En segundo lugar, las reglas de funcionamiento interno de las Cámaras integrantes de las Cortes Generales, contribuyen también a esa doble función de preeminencia del Ejecutivo y fortalecimiento de los partidos políticos. El diseño constitucional ya

6 Fernández-Miranda Campoamor, A., «Sobre la forma de gobierno: ¿un exceso de racionalización?», ob. cit., p. 856.

7 Paniagua Soto, J.L., «Sobre la forma de gobierno parlamentario en España: un parlamentarismo racionalizado de corte presidencial», ob. cit., p. 3.

8 De «sistema electoral formalmente proporcional pero con efectos claramente mayoritarios» ha hablado S. Gambino. Gambino, S., «Sistema electoral y forma de gobierno en España: un éxito del parlamentarismo racionalizado», en García Roca, F.J. y Alberti Rovira, E. (coords), Treinta años de Constitución, Tirant lo Blanch, 2020, p. 921.

9 Fernández-Miranda Campoamor, A., «Sobre la forma de gobierno: ¿un exceso de racionalización?», ob. cit.,p. 859.

(C) UNED. Revista de Derecho Politico

N. o 111, mayo-agosto 2021, págs. 109-136 
aparecía dibujado en los Reglamentos Provisionales de las Cortes ${ }^{10}$, cuyas bases pasarían a la regulación posterior configurando las líneas maestras de nuestro Derecho Parlamentario actual. En ellos se hace recaer todo el protagonismo en los grupos parlamentarios, frente a los parlamentarios individualmente considerados, que prácticamente no conservan facultades individuales más allá de la facultad de presentar preguntas y solicitudes de información. Además, la posibilidad de contar con medios técnicos, que se articula a través de una subvención para el funcionamiento ordinario, se atribuye a los Grupos Parlamentarios siendo prácticamente imposible, más allá del Grupo Mixto, que los representantes puedan disponer de las mismas para apoyar su labor al margen de la organización que su propio grupo haya previsto.

Asimismo, se refuerzan las mayorías parlamentarias en el funcionamiento ordinario de las Cámaras, dejando a las minorías con muy pocas opciones para desempeñar su labor al margen del concurso de la voluntad del grupo o grupos que sustentan al gobierno. En este sentido, los representantes de opciones minoritarias por sí solos no pueden decidir el orden del día de las sesiones ni las admisiones a trámite o la dirección de los debates, los cupos de iniciativas, etc. Tampoco en la elección de los órganos de dirección, Mesa y Presidencia, las minorías se encuentran debidamente representadas de manera que las trabas para la oposición parlamentaria van mucho más allá de su debilidad numérica para adoptar acuerdos y pueden acabar dejándolas prácticamente aisladas. De esta manera, el diseño constitucional aboga por un Parlamento en el que los grupos mayoritarios tienen todo el protagonismo, contribuyendo a reforzar así la posición de los partidos políticos mayoritarios.

En lo que respecta al mismo diseño del sistema parlamentario de gobierno, la regulación constitucional hace descansar todo el protagonismo en la presidencia, al ser la depositaria única de la confianza parlamentaria. Ello es así porque la investidura únicamente vincula al Congreso de los Diputados con la persona candidata luego investida, sin que esa relación de confianza se extienda al resto del Gobierno. Como es sabido, el titular de la presidencia del Gobierno tiene libertad para nombrar y separar a sus ministros sin que ello tenga que ser aprobado por el Congreso. En segundo lugar, la facultad de disolución de las Cámara es atribuida a la presidencia en exclusiva, así como la de presentar una cuestión de confianza, que requiere de deliberación previa en el Consejo de Ministros pero que recae en la presidencia del ejecutivo, reforzando ese vínculo con la Cámara Baja (artículos 112 y 115 CE). Para terminar, en caso de pérdida de confianza en el Ejecutivo, el Congreso de los Diputados únicamente puede hacer valer ese descontento en la figura de la presidencia del Gobierno, sin que sea posible articularlo en la figura de cualquier otro miembro del Consejo de Ministros, que responde de manera solidaria (artículo 108 CE). También el carácter constructivo de la moción de censura obliga al Congreso de los Diputados a proponerla en torno a otra persona candidata para ocupar la presidencia.

10 Reglamento Provisional del Congreso de los Diputados, de 13 de octubre de 1977 y Reglamento Provisional del Senado de 14 de octubre de 1977. 
Para terminar con este breve bosquejo, recordar como la opción por las listas cerradas y bloqueadas, hace descansar todo el poder en las cúpulas de los partidos que controlan no sólo quien concurrirá a las elecciones sino el orden en el que lo hará. Asimismo, el partido decide la composición de la dirección del grupo parlamentario así como las posibles portavocías que cada uno de sus miembros podrá ocupar. Y administra una parte importante, por no decir toda la subvención del Grupo Parlamentario, disponiendo su destino en los márgenes que permite la Ley Orgánica 8/2007, de 4 de julio, sobre Financiación de Partidos Políticos, que son bastante amplios.

Todo esto refuerza el control del partido sobre sus representantes parlamentarios que a día de hoy tienen que acomodar sus posiciones a las decididas por el partido fuera de las instituciones. Ello ha contribuido a la fortaleza de nuestros partidos, hasta el punto de que en la práctica, el partido o partidos que gobiernan colocan a sus cúpulas al frente del Ejecutivo, colocando paradójicamente a su grupo parlamentario en una posición de subalternidad. De esta manera, la dialéctica propia del sistema parlamentario entre Parlamento y Gobierno se traduce en una contraposición mayoría-minorías, no sólo por las dinámicas propias del sistema parlamentario, sino además por las propias del funcionamiento de partidos políticos fuertemente jerarquizados.

Pocas dudas pueden caber de que este diseño cumplió con creces su misión y hemos gozado de años de estabilidad, que han permitido consagrar un sistema fuertemente asentado en partidos políticos poderosos, dos a nivel estatal, que se han ido alternando en el poder con necesidad tan sólo de apoyos puntuales que les prestaban los partidos nacionalistas vascos y catalanes.

Este panorama cambia a raíz de la crisis desatada en 2007 y que tuvo uno de sus puntos álgidos en un movimiento sin precedentes en nuestra historia más reciente, el 15-M, en 2011, que puso voz a un sentimiento de desafección ciudadana con la clase política que había ido creciendo en los años precedentes. La necesidad de reformas estructurales del sistema, que abogaran por una mayor participación ciudadana en la vida política, así como mayor transparencia en las instituciones para luchar contra la corrupción y la reforma del sistema electoral para hacerlo más proporcional son algunas de sus reivindicaciones principales. El movimiento provocó la aparición de nuevos actores políticos, Podemos y Ciudadanos, que cambiarían el escenario electoral español, dando lugar al principio del fin del bipartidismo tal y como lo habíamos vivido desde la Transición. A todo ello hay que sumar el conflicto catalán, que empieza con la aprobación de un nuevo Estatuto de Autonomía para Cataluña en 2007, recurrido ante el Tribunal Constitucional por diputados del Partido Popular y resuelto en $2010^{11}$.

11 Desde ese momento, el conflicto político no para de agravarse. La STC 31/2010, de 28 de junio, que resuelve este recurso de inconstitucionalidad interpuesto por diputados del Partido Popular frente al Estatuto de Autonomía de Cataluña, podría ser considerada como uno de los momentos clave en un proceso de desconexión mutua que no pararía de enrarecerse desde entonces. 
Estos hechos acaban provocando enormes desajustes, que afectarían sobre todo al funcionamiento del único órgano legitimado democráticamente de manera directa, el Parlamento, que ha atravesado un período de parálisis institucional que arranca a finales de 2015 y podría haber terminado en diciembre de 2019, con el primer gobierno de coalición de nuestra reciente historia democrática. Sin embargo, la configuración de las Cámaras y, sobre todo del Congreso de los Diputados, con casi una veintena de formaciones políticas presentes, incluida una agrupación electoral por primera vez en nuestra historia y el anuncio de una próxima convocatoria electoral en Cataluña con fecha indeterminada, realizada por el Presidente de la Generalitat en enero de 2020, no vaticinaba un período de tranquilidad demasiado largo.

En medio de ese escenario y con un gobierno que todavía no había empezado casi a andar, estalla una crisis sanitaria mundial provocada por la pandemia de Coronavirus que lleva al Gobierno español, como a tantos otros, a decretar el estado de alarma, con confinamiento de la población incluido, y a paralizar todo el país durante semanas. La crisis, sin precedentes, afecta al funcionamiento de todos los sectores económicos, excepto los considerados esenciales, que tienen que parar su actividad para frenar la ola de contagios que se estaba produciendo.

Paradójicamente, dado que la Constitución destaca que durante la vigencia de los estados excepcionales el Congreso de los Diputados tiene que estar reunido, esta situación afecta al funcionamiento del Parlamento, que ve reducida su actividad al mínimo. Pero eso lo analizaremos en otro lugar. En este trabajo vamos a centrarnos en el período destacado, de diciembre de 2015 hasta noviembre de 2019, los años en que el Parlamento no cumplió con su labor.

\section{LA ACTIVIDAD PARLAMENTARIA EN EL PERÍODO 2011-2015: UN PARLAMENTO DILUIDO}

Resulta llamativo, a mi juicio, que un sistema diseñado para lograr la estabilidad gubernamental y preparado teóricamente para un Parlamento complejo, no haya sido capaz de dar respuesta a la aparición de nuevos partidos que ponen en cuestión el bipartidismo reinante hasta muy poco tiempo antes.

Da la impresión de que el sistema se había adaptado tan bien a la alternancia política de los dos grandes partidos, con pocos sobre saltos, que se ha visto desbordado por el cambio producido en la composición parlamentaria. Cambio, por lo demás, mitigado por nuestro sistema electoral, y el efecto de reducción de la complejidad que provoca.

En las páginas que siguen vamos a analizar los síntomas que a nuestro juicio demuestran que el Parlamento en el período analizado se ha convertido en un órgano incapaz de cumplir ninguna de sus misiones constitucionales, poniendo así en jaque la legitimidad de todo el sistema. Vayamos por partes. 


\section{La investidura de la presidencia del gobierno como primera misión parlamentaria}

No cabe duda de que la investidura de la presidencia del Gobierno es la principal misión que las Cortes Generales recién salidas de las urnas tienen encomendada. Tarea que, como es sabido, el artículo 99 CE atribuye al Congreso de los Diputados y que requiere la intervención de la Jefatura del Estado y de la presidencia de las Cortes. Esto último, lejos de ser baladí, podría contribuir a explicar algunos de los problemas que se han sucedido en los últimos años para investir a la persona candidata. Pocos podían augurar que íbamos a vivir en un período tan corto la disolución anticipada de las Cámaras en dos ocasiones ante la falta de acuerdo para la investidura, tal y como establece el artículo 99.5 CE.

La primera se produce en la XI Legislatura, tras las elecciones del 20 de diciembre de 2015. La segunda es más reciente aún, la XIII Legislatura, tras el 28 de abril de 2019. Además del hecho de la disolución anticipada en sí, por falta de acuerdo, resulta relevante la manera en que se desarrollaron ambos procesos, sin que pareciera que los candidatos del partido mayoritario en cada ocasión tuvieran mucho interés o prisa en someterse a la confianza de la Cámara.

Tras las elecciones de 20 diciembre de 2015, asistimos al hecho insólito e inédito entre nosotros, de que tras la primera ronda de consultas del monarca con los representantes de los distintos partidos con representación parlamentaria, el candidato propuesto, Mariano Rajoy, renuncia a someterse al proceso de investidura con el argumento de que no contaba con los votos suficientes ${ }^{12}$. El desenlace ya lo conocemos. Semanas después el candidato del Partido Socialista, Pedro Sánchez, llega a un acuerdo con Ciudadanos y se postula como candidato. La votación tiene lugar en marzo de 2016 y fracasa. No hay nuevas propuestas ni votaciones y se disuelven las Cámaras el 3 de mayo de ese año.

Con independencia del lugar en que la renuncia del candidato a ser investido deja a la institución parlamentaria, que es la que tiene la última palabra, hay que considerar si el encargo que otorga la Presidencia del Congreso tiene que ser forzosamente cumplido por la persona designada. Todos sabemos que el Parlamento ha dejado de ser un lugar de debate, reflexión y adopción de acuerdos. Los pactos se negocian fuera, por las cúpulas de los partidos políticos y en muchas ocasiones más influenciados por gurús de la comunicación política que por pesos pesados de la organización. Sin embargo, renunciar al encargo a la primera porque no se quiere pasar por el trance de debatir y recibir el voto negativo de la Cámara deja al Congreso de los Diputados, al Parlamento, muy mal parado ${ }^{13}$. Supone la asunción de que la exposición del programa

12 El Partido Popular, pese a ser el mayoritario, contaba sólo con 112 escaños. El Partido Socialista con 78 y Ciudadanos con 40 .

13 Una posición radicalmente distinta defiende Blanco Valdés, que aludiendo a este hecho en concreto, considera que «Mariano Rajoy, en tanto que ganador el 20 de diciembre, no solo no estaba obligado, ni jurídica ni políticamente, a aceptar un eventual encargo del rey para someter su candidatura al Congreso de los Diputados, sino que su negativa a acudir a la Cámara a solicitar su confianza fue 
electoral por parte de la persona candidata y su posterior debate no tienen la más mínima posibilidad de incidir sobre la posición ya fijada de los distintos partidos presentes en el Congreso.

La posibilidad de renuncia a la candidatura no es una cuestión pacífica entre nosotros. A mi juicio, esta posibilidad no se compadece con el espíritu constituyente. La propuesta no siempre se puede construir sobre certezas ${ }^{14}$, pero creo que debe ser la presidencia del Congreso de los Diputados la que la haga en base a las posibilidades reales de resultar investido y, si no existen, de proponer a la persona que cuenta con más apoyos parlamentarios en el Congreso de los Diputados, ya sea por sus propios escaños o por los suyos sumados a los de otras fuerzas que han anunciado su voto favorable, teniendo en cuenta también aquellos que anuncian su abstención.

Con este escenario, Pedro Sánchez, a pesar de no contar con los apoyos suficientes para lograr la investidura, solicitó ser propuesto como candidato. El anuncio fue recibido con alivio dado que la negativa de Rajoy impedía poner en marcha el plazo de dos meses desde la primera investidura fallida que el 99.5 CE determina como término temporal inicial para la disolución de las Cortes y la convocatoria de nuevas elecciones. Pedro Sánchez, como era previsible, no resultó investido y tras el agotamiento del plazo de los dos meses previstos en la Constitución se produjo la disolución y la consiguiente convocatoria electoral, sin que mediara un nuevo intento.

Creo que Rajoy nunca debió negarse a someterse a la investidura. Al menos, el paso al frente de Pedro Sánchez tras su acuerdo con Ciudadanos se produjo tras una nueva ronda de consultas con el Rey. Todavía habría otra, en abril de 2016, antes de que se cumpliera el plazo de dos meses a partir de la primera votación fallida que el artículo 99.5 CE establece como límite para la disolución automática de las Cortes Generales.

En la doctrina se ha discutido acerca de la situación de bloqueo que podría darse de no producirse el primer debate de investidura, a partir del cual empiezan a contar los dos meses de plazo que da la Constitución para investir al titular de la presidencia. $\mathrm{Y}$ para salvar ese escollo algunos proponen una reforma constitucional que de una manera u otra impida que esa situación se produzca ${ }^{15}$. A mi juicio, la falta de previsión

\footnotetext{
lo verdadera y plenamente coherente con la naturaleza de la institución prevista en el art. 99 de la CE a la vista del hecho de que no tenía ni la más remota posibilidad de ser investido una vez que los líderes de los grupo políticos con representación parlamentaria que representaban a más de la mayoría absoluta del Congreso informaron al rey, tras hacerlo a la opinión pública, del sentido negativo de su voto». Blanco Valdés, R., «El año en que vivimos peligrosamente: del bipartidismo imperfecto a la perfecta ingobernabilidad», Revista Española de Derecho Constitucional, 109, 2017, p. 90.

14 En este sentido, Belda sostiene que «ya se ha afirmado, y la realidad de las Legislaturas XI y XII lo han demostrado que, en situaciones de ausencia de mayorías, la propuesta regia se construye sobre posibilidades numéricas de aproximación a los votos exigibles para la investidura, y no en certezas sobre el resultado». Belda, E, «Investidura del presidente del Gobierno y función ordenadora de la Presidencia del Congreso", Revista General de Derecho Constitucional, 27, 2018, p. 29.

15 A este respecto, Blanco Valdés, R., «El año que vivimos peligrosamente: del bipartidismo imperfecto a la perfecta ingobernabilidad», ob. cit., pp. 92 y 93. Asimismo, Mateos y De Cabo, O., «La
} 
constitucional con respecto a cuándo debe realizarse la primera votación, no es tal. En otras palabras, el constituyente no vio necesario regular qué sucede cuando no hay candidato dispuesto a someterse a la investidura, porque no pensó que tal supuesto pudiera darse. El constituyente, confiado en la centralidad del Parlamento como lugar de reflexión, debate y toma de decisiones, no consideró siquiera esa posibilidad. Por muy fragmentado que pueda estar el Congreso de los Diputados, siempre habrá una candidatura con más opciones que las demás. De esta manera, considero que en nuestro diseño constitucional no cabe la negativa del candidato con más opciones.

La segunda disolución anticipada se produce tras las elecciones de 28 de abril de 2019, con un proceso en el que el partido mayoritario parece desde el principio más interesado en la repetición electoral que en lograr la investidura de su candidato. Tanto es así que se produce un único intento tras el encargo a Pedro Sánchez por parte del Jefe del Estado. El debate y votación de investidura se celebra en julio, sin éxito y las Cámaras se disuelven sin que se produzca un nuevo intento. Nunca sabremos qué hubiera sucedido si esa segunda oportunidad se hubiera presentado. Aunque algunos tenemos la duda más que razonable de que el candidato podría haber salido investido en segunda vuelta, con la mayoría simple de los votos, gracias a la abstención de la fuerza llamada a ser su socio de gobierno, Unidas Podemos, que no parecía interesada en una repetición electoral.

A mi juicio, la disolución de las Cortes Generales tras una única sesión de debate y votación de investidura reviste mucha gravedad. ¿Era seguro que no se iba a contar con el apoyo o la abstención de alguna fuerza política? ¿O es que era preferible una repetición electoral? ¿qué margen tiene la presidencia del congreso? ¿Y la jefatura del Estado?

Estas últimas preguntas nos parecen pertinentes porque la presidencia del Congreso de los Diputados es una institución que no se ha caracterizado precisamente por servir a los intereses de toda la Cámara en su conjunto. Muy al contrario, entre nosotros, resulta relativamente habitual que el partido mayoritario en el Congreso, que ocupa el gobierno además, se sirva de la presidencia como un elemento más estabilizador de su posición, poniendo sus decisiones al servicio de la mayoría. Pocas dudas hay de que la presidencia del Parlamento no es una figura independiente del partido por el que concurrió a las elecciones su titular. En momentos clave como la investidura, su participación, que suele pasar desapercibida, es crucial a la hora de convocar o no una sesión de investidura o dejar pasar el tiempo de dos meses marcado en el artículo 99.5 CE hasta provocar la repetición electoral. Ni más ni menos. También decide la convocatoria de los Plenos, lo que de facto supone que decide la puesta en marcha del Parlamento en ese período de tiempo que media entre las elecciones y la investidura ${ }^{16}$.

elección parlamentaria del presidente del Gobierno en España: análisis normativo, estabilidad institucional y propuesta de reforma del artículo 99.5 de la Constitución Española», Revista Española de Derecho Constitucional, 111, p. 178 y ss.

16 Sobre esta cuestión puede consultarse mi trabajo Gómez Corona, E., «Las limitaciones del Parlamento recién constituido durante la prorrogatio gubernamental», Revista de Derecho Político, 96, 2016.

(C) UNED. Revista de Derecho Politico

N. o 111, mayo-agosto 2021, págs. 109-136 
Sabemos que la Constitución no regula el número de veces que se tiene que intentar, mediante debate y votación, la investidura de la persona candidata. Hacerlo no se acomodaría a la necesaria flexibilidad que requiere un proceso de negociación de este tipo. Sin embargo, cabe preguntarse si está en manos de la presidencia del Congreso decidir si tras una nueva ronda de consultas propone o no a otro candidato, o al mismo, en sucesivas ocasiones. Dicho de otro modo. ¿Es suficiente la voluntad del partido mayoritario, que ostenta la presidencia del Congreso de los Diputados, para provocar una repetición electoral aun cuando existen dudas de si se dispondrá de los apoyos necesarios para investir a su candidato?

Considero que si existen posibilidades, aunque no sean certezas, de que la investidura salga adelante, no existen más opciones que plantear una nueva votación tras el oportuno debate. No hacerlo supone alterar las reglas del juego con intereses partidistas y, con toda probabilidad, electorales. No creo que pueda dejarse correr el plazo de dos meses de manera interesada por el miedo a conseguir una investidura cuando se prefiere la repetición electoral.

En el caso del Jefe del Estado, su papel es meramente simbólico, recayendo la responsabilidad en la Presidencia del Congreso, que refrenda la propuesta regia. Sin embargo, no hay que desdeñar el papel del monarca en todo el proceso dado el carácter de árbitro o mediador que le atribuye la Constitución y, la facultad de realizar nuevas rondas de contactos que podrían añadir, o no, presión a los principales actores.

$\mathrm{Al}$ margen de la respuesta que demos a estas cuestiones, lo que parece claro es el poco respeto por la institución parlamentaria que denotan estas actitudes. Y el hecho de que la disolución lleve aparejada una nueva llamada al cuerpo electoral no resta un ápice de validez a estas críticas. Una vez que la ciudadanía ha expresado su posición en las urnas, corresponde a los actores políticos involucrados traducir esa voluntad en un gobierno. No hacerlo sin agotar todas las posibilidades, es una falta de respeto a la ciudadanía.

\section{El fin del principio de anualidad presupuestaria}

Como señalara Rodríguez Bereijo hace más de 50 años, en la potestad de elaboración y aprobación de los Presupuestos se materializa, como en ninguna otra, la estrecha colaboración entre el Gobierno y el Parlamento, de manera que estudiar el Presupuesto es penetrar en el fondo de los problemas constitucionales y, particularmente en los regímenes democráticos de separación de poderes, es plantearse el estudio de las relaciones entre el poder Legislativo y el Poder Ejecutivo ${ }^{17}$. Además de ello, añadiría, en los regímenes parlamentarios, el Presupuesto constituye la prueba de fuego de los Gobiernos en minoría, pues permite medir el grado de apoyo con que cuentan, su

17 Rodríguez Bereijo, A., «La limitación de la iniciativa parlamentaria en materia presupuestaria en el Derecho positivo español», Revista de la Facultad de Derecho de la Universidad de Madrid, 33, 1968, pp. 439 y 440. 
capacidad de liderazgo y las posibilidades de manejar situaciones de — posible- geometría variable ${ }^{18}$. De esta forma, Presupuestos y estabilidad parlamentaria han ido de la mano en nuestro país, dado que la no aprobación de las cuentas gubernamentales supone un revés de tal envergadura que obliga a dimitir al Gobierno de turno, abocando a nuevas elecciones generales ${ }^{19}$. No es posible seguir gobernando después de que las Cortes hayan tumbado el programa económico, que no es más que una traducción del programa político, del Ejecutivo. El sistema parlamentario se basa precisamente en eso, en la confianza que el Congreso de los Diputados tiene en el Gobierno.

Ciertamente, a estas alturas sabemos que cuando el artículo $134 \mathrm{CE}$ atribuye al Gobierno la elaboración del presupuesto y a las Cortes Generales, su examen, enmienda y aprobación, no está reflejando la realidad de las cosas. El Gobierno no sólo elabora el proyecto sino que pilota todo el proceso gracias a una serie de limitaciones que dificultan enormemente su debate y enmienda por parte de las Cámaras. El famoso veto de las enmiendas que incrementen el gasto o la necesidad de presentar las enmiendas compensadas, unido a la rapidez en la tramitación, que impide un debate ni mínimamente sosegado para tratar la cuestión, dificultan enormemente la reforma del proyecto inicialmente presentado por el gobierno ${ }^{20}$. A ello ha venido a sumarse en los últimos años, tras la reforma del 135 CE de 2011 y la aprobación de la Ley Orgánica de Estabilidad Presupuestaria, una limitación extra a la capacidad prevista en el artículo $134 \mathrm{CE}$.

Y sin embargo, la intervención del Parlamento resulta crucial para dar cumplimiento a un principio elemental de cualquier Estado de Derecho: sin presupuestos no se puede funcionar porque el Estado no puede efectuar gastos que no aparezcan reflejados en el mismo. No olvidemos que el presupuesto en relación con los gastos funciona como autorización. Por todo ello, la aprobación del Presupuesto constituye el momento político más importante tras la celebración de elecciones generales y la subsiguiente investidura de la presidencia del Gobierno.

18 Recordemos como la imposibilidad del Gobierno Sánchez de aprobar los presupuestos para 2019, bien avanzado ya ese año, sirvieron como argumento para disolver las Cortes Generales y convocar nuevas elecciones que se celebraron el 10 de Noviembre de ese año.

19 En 1983, el Gobierno de Calvo-Sotelo, ante su debilidad parlamentaria, no elaboró Presupuestos y convocó elecciones. Tuvo que ser el nuevo Gobierno de Felipe González el que, con retraso, aprobase los Presupuestos correspondientes. En 1996, el proyecto de presupuestos fue enmendado a la totalidad por el Parlamento y el Gobierno convocó elecciones. Tras las elecciones, el nuevo Gobierno de Aznar, que tomó posesión en mayo, renunció a reelaborar los Presupuestos 1996 por falta de tiempo, prorrogándose el resto del año los Presupuestos de 1995. Ya en 2012, el Gobierno de Rodríguez Zapatero no elaboró los Presupuestos de 2012 por su debilidad parlamentaria y convocó elecciones anticipadas. El nuevo Gobierno de Rajoy tuvo que elaborar unos Presupuestos, que entraron en vigor con retraso.

20 No es este el lugar para recordar las numerosas limitaciones con las que las Cortes Generales se enfrentan al examen, enmienda y aprobación de las cuentas públicas. Hemos tratado este tema en otro lugar, Gómez Corona, E., «Las potestades financieras de las Cortes Generales: del uso al abuso del veto presupuestario sobre las enmiendas con repercusión financiera», Revista General de Derecho Constitucional, 28, 2018.

N. ${ }^{\circ} 111$, mayo-agosto 2021, págs. 109-136 
En el ejercicio de la potestad presupuestaria se aprecian irregularidades en el período de tiempo analizado. La primera, de las muchas con las que se salda este tiempo, en 2015, año en el que el Gobierno de Rajoy, ante la inminencia de unas elecciones en diciembre y lo incierto del resultado, aprueba un presupuesto, el quinto de su gobierno, el 29 de octubre de 2015, saldando la legislatura con un total de cinco presupuestos aprobados. La presentación del proyecto se produjo el 4 de agosto de 2015 . Nunca antes un gobierno había pretendido - y logrado — condicionar la acción política de su sucesor aprobando unas cuentas in extremis justo antes de las elecciones.

Aunque el plazo de aprobación no distara mucho del que viene siendo habitual, el hecho de que se presentaran el 4 de agosto ya denota la intención firme de dejar las cuentas aprobadas para el siguiente ejercicio económico. La cuestión no es baladí si se tiene en cuenta el papel del presupuesto como plan económico de un gobierno y lo necesario que resulta que haya correspondencia con el programa que lleva a una fuerza a obtener los escaños suficientes para investir a su candidato como presidente. Por ello, lo habitual en nuestro sistema parlamentario, una vez que había elecciones convocadas para final de año, es no aprobar el presupuesto para dejar que el Ejecutivo salido de las urnas aprobara sus propias cuentas cuando pudiera, no teniendo que estar maniatado por las cuentas de un gobierno anterior, que seguro tendría otras prioridades políticas distintas, reflejadas en un programa económico diferente.

Esos Presupuestos prematuramente aprobados por el Gobierno Rajoy para el ejercicio 2016, tendrían una vigencia inusitada, ya que fueron prorrogados hasta mediados de 2017, el 27 de junio, fecha en que pudieron aprobarse los de ese año ${ }^{21}$. A su vez, las cuentas de 2017 , se prorrogaron hasta julio de $2018^{22}$, fecha en la que se aprobaron los nuevos y que a día de hoy todavía continúan vigentes tras una prórroga en 2019 y otra en 2020. Hubo un intento de aprobar unos presupuestos en 2019 para 2020, pero no salieron adelante y acabó justificando la disolución de las Cámaras meses después de que Sánchez hubiera alcanzado la presidencia del gobierno a través de una moción de censura.

Más allá de la irregularidad que supone que el gobierno encuentre dificultades para aprobar los Presupuestos y que esto se repita año tras año, hemos asistido al abuso del veto presupuestario por parte del Gobierno para tratar de evitar la tramitación de iniciativas legislativas de las Cámaras ${ }^{23}$. Esta práctica, que ha llegado hasta extremos difícilmente explicables, fue finalmente declarada inconstitucional por el Tribunal Constitucional pero supuso la parálisis de la iniciativa legislativa del Congreso de los Diputados durante meses. Lo llamativo de esta situación no es tanto que el Gobierno plantease el veto, como que la Mesa del Congreso de los Diputados aceptase una y

${ }^{21}$ El proyecto de ley de presupuestos para 2017 fue presentado por el Gobierno ante el Congreso de los Diputados el 4 de abril, siendo aprobado finalmente el 27 de junio de 2017.

22 Aprobados el 3 de julio de 2018, se presentaron ante el Congreso el 3 de abril de ese mismo año.

23 Al respecto puede consultarse mi trabajo «Las potestades financieras de las Cortes Generales: del uso al abuso del veto presupuestario sobre las enmiendas con repercusiones presupuestarias», Revista General de Derecho Constitucional, 28, 2018. 
otra vez el ejercicio de una competencia, al margen de los límites establecidos en la legalidad parlamentaria, alterando de esta forma el equilibrio de poderes entre el Ejecutivo y Legislativo, a favor, claro está, del primero. En el epígrafe siguiente abordaremos esta cuestión con algo más de detenimiento.

Sea como fuere, a día de hoy podemos afirmar que el Parlamento ha dejado de ser, no la institución central en materia presupuestaria de acuerdo con el artículo 134 $\mathrm{CE}$, sino ni siquiera un órgano necesario en lo relativo a las cuentas. Hasta hace no mucho, la aprobación de un Presupuesto que respondiera a las prioridades políticas del Ejecutivo, constituía un paso imprescindible para seguir ejerciendo de tal, hasta el punto de que el Gobierno que no conseguía sacar adelante sus cuentas, convocaba nuevas elecciones ${ }^{24}$. Ese fue el argumento esgrimido por Pedro Sánchez tras el rechazo a sus cuentas para 2019, que acabó disolviendo las Cortes y convocando elecciones para el 28 Abril de 2019.

En los últimos tiempos sin embargo, los Gobiernos deciden si cumplir con la función constitucional de presentar las cuentas ante el Congreso antes del 31 de octubre de cada año o, por el contrario y ante la eventualidad de no contar con la aprobación parlamentaria de su plan económico anual, no hacerlo y continuar trabajando con presupuestos prorrogados. De esta manera, la preeminencia del Gobierno que antes venía provocada por su control sobre una mayoría parlamentaria, ahora se traduce en un desprecio a las Cámaras con el consiguiente descrédito para la soberanía popular que encarnan.

Lamentablemente, la declaración del estado de alarma por la crisis del coronavirus y todo lo que le ha sucedido, no permite saber cuándo habría presentado el Gobierno de coalición PSOE-UP su proyecto de presupuestos en condiciones de normalidad. Pero, lo acontecido en los últimos años permite afirmar que el Presupuesto ha dejado de ser el instrumento principal con que cuentan los gobiernos para llevar a cabo sus políticas, a no ser que la principal tarea de los gobiernos en esta nueva época sea la de asegurar su propia supervivencia, más que la de hacer políticas propias con incidencia real en el conjunto de la ciudadanía.

\section{El Parlamento que no legisla}

Si hay algo que no podríamos achacar de ninguna manera a la crisis del bipartidismo y a lo sucedido en los últimos años es la pérdida de centralidad del Parlamento en tanto que órgano fundamentalmente legislador. La sustitución de las leyes por Decretos-ley gubernamentales es una tendencia generalizada en nuestro país, no sólo por el sistema central, también en los autonómicos desde que se introdujera esta posibili-

24 Así pasó en el año 1995, cuando CiU retiró su apoyo al gobierno del Partido Socialista, que no pudo aprobar sus cuentas. Felipe González disolvió entonces las Cortes Generales, cuando no habían transcurrido ni tres años de legislatura y las nuevas elecciones tuvieron lugar en marzo de 1996.

(C) UNED. Revista de Derecho Politico

N. ${ }^{\circ} 111$, mayo-agosto 2021, págs. 109-136 
$\operatorname{dad}^{25}$. El Tribunal Constitucional ha tratado de poner freno, a mi juicio sin éxito, a esta práctica que en los últimos años se ha visto muy acentuada ${ }^{26}$. No es de extrañar teniendo en cuenta que, como ha señalado Carmona Contreras, «las ventajas inherentes a esta herramienta normativa actúan como una tentación irresistible para cualquier Gobierno, ya que posibilita la aprobación de normas con valor de ley al margen tanto del Parlamento como del procedimiento legislativo y que, asimismo, entran inmediatamente en vigor a partir de su publicación en el Boletín Oficial del Estado» ${ }^{27}$.

Si se observa lo sucedido desde 2007, año del que hemos partido porque es cuando empieza a fraguarse la crisis que nos ha traído hasta aquí, observamos cómo hasta llegar a 2015, sólo en una ocasión el número de Decretos-Ley aprobados superó al de leyes ordinarias (2012). Sin embargo, si reparamos en el período que estamos estudiando, desde 2016 hasta la actualidad, observamos como eso ha pasado sistemáticamente todos los años.

\begin{tabular}{|c|c|c|c|c|}
\hline AÑO & $\begin{array}{c}\text { LEYES } \\
\text { ORGÁNICAS }\end{array}$ & $\begin{array}{c}\text { LEYES } \\
\text { ORDINARIAS }\end{array}$ & DECRETOS-LEY & $\begin{array}{c}\text { DECRETOS- } \\
\text { LEGISLATIVOS }\end{array}$ \\
\hline 2007 & 16 & 56 & 11 & 2 \\
\hline 2008 & 2 & 4 & 10 & 2 \\
\hline 2009 & 3 & 29 & 14 & 0 \\
\hline 2010 & 9 & 44 & 14 & 1 \\
\hline 2011 & 12 & 38 & 20 & 3 \\
\hline 2012 & 8 & 17 & 29 & 0 \\
\hline 2013 & 9 & 27 & 17 & 0 \\
\hline 2014 & 8 & 36 & 17 & 8 \\
\hline 2015 & 16 & 48 & 12 & 0 \\
\hline 2016 & 2 & 0 & 7 & 0 \\
\hline 2017 & 1 & 12 & 21 & 28 \\
\hline 2018 & 5 & 11 & & \\
\hline
\end{tabular}

25 El Decreto-Ley no se introduce en los ordenamientos autonómicos hasta que se aprueban los Estatutos de Autonomía llamados de segunda generación, estando vigente hasta ahora en Navarra, Extremadura, Andalucía, Aragón, Baleares, Cataluña, Comunidad Valenciana, Castilla y León, Murcia y Canarias. Para un balance sobre su uso hasta 2011 puede consultarse Herráiz Serrano, O., «Teoría y práctica del Decreto-ley autonómico tras su incorporación al sistema de fuentes en algunas Comunidades», Corts. Revista de Derecho Parlamentario, 25, 2011.

26 Hasta 2007 no se produce la primera declaración de inconstitucionalidad de un Decreto-Ley basada en la falta del presupuesto habilitante, la extraordinaria y urgente necesidad. Se trataba de la reforma del sistema de pensiones por desempleo aprobado en 2002 por el Gobierno Aznar. Desde entonces, en no pocas ocasiones, el Tribunal Constitucional ha constatado y declarado este hecho, anulando la norma con rango de ley.

${ }_{27}$ Carmona Contreras, A., «Decretos-Leyes: el medio y los fines», Agenda Pública, 8 de marzo de 2019 . 
Podría argumentarse, con razón, que muchos gobiernos han recurrido al Decreto-ley incluso cuando han contado con mayorías cómodas en la Cámara —incluso mayorías absolutas- haciendo una interpretación del artículo 86.1 CE, que dista mucho de la intención del constituyente. Sin embargo, no cabe duda de que su uso se ha normalizado entre nosotros y se ha acentuado mucho más en los últimos meses. De hecho, las cifras de Decretos-ley aprobadas desde la declaración de la emergencia sanitaria, estado de alarma incluido, así lo constatan ${ }^{28}$.

Los problemas que tiene el recurso al Decreto-ley han sido suficientemente descritos por la doctrina y no tiene sentido abundar en ellos ${ }^{29}$. Quede constancia, eso sí, de que hay una importante diferencia entre recurrir al Decreto-ley con frecuencia pero sin dejar de hacer uso de la normal potestad legislativa de las Cortes y gobernar en base casi exclusivamente a Decretos-ley en un contexto en el que no se aprueban leyes parlamentarias. En los últimos años no coexisten dos centros de elaboración de normas con rango de ley - Parlamento y Gobierno-, por llamarlo de alguna manera, sino que el Parlamento se ha visto sustituido, enteramente sustituido en algunos períodos, por el Gobierno, que sólo puede aprobar normas sujetas a importantes limitaciones materiales en cuanto a los contenidos que pueden afectar. El saldo total de los años 2016 a 2019 es revelador: 11 leyes orgánicas en 4 años y 28 leyes ordinarias frente a 74 Decretos-ley. También es cierto que los Decretos-ley, para dejar de ser normas provisionales e incorporarse definitivamente al ordenamiento tienen que ser convalidados por el Congreso de los Diputados. Pero esta convalidación, como es de sobra sabido, impide cualquier tipo de participación de los grupos parlamentarios. Únicamente en el caso, improbable, de que se opte por tramitar como Ley un Decreto-ley veremos este tipo de participación aunque será para la aprobación de una norma distinta, no lo olvidemos.

Es cierto que durante este período ha habido un tiempo considerable de vigencia de gobiernos en funciones y Cámaras disueltas ${ }^{30}$, pero eso en modo alguno justifica la adopción de tantos Decretos-ley y el abandono de la ley parlamentaria, que como vemos, va camino de convertirse en un hecho.

Tener que recordar a estas alturas, cuando han pasado más de 40 años desde la aprobación de la Constitución, el sentido que tiene en un sistema parlamentario que

28 A fecha 17 de octubre, en 2020 se había aprobado una única ley orgánica, cinco leyes ordinarias y treinta y un Decretos-Ley.

29 Véase, por todos, Carmona Contreras, A.M., La configuración constitucional del Decreto-ley, Madrid, Centro de Estudios Políticos y Constitucionales, 1997.

30 La X Legislatura se disuelve el 27 de octubre de 2015. La XI Legislatura abarca del 13 de enero de 2016 a 3 de mayo de 2016. La XII, del 19 de julio de 2016 a 5 de marzo de 2019. Y la XIII, de 21 de mayo de 2019 a 24 de septiembre de 2019. El 3 de diciembre de 2019 se constituyó la XIV Legislatura, la actual. 
la potestad legislativa se atribuya al único órgano de representación directa de la sociedad, constituye un estrepitoso fracaso del sistema que el constituyente diseñó. Las alusiones al cambio de función de la ley, que ya no se corresponde tanto con el ideal de la norma general y abstracta, sumado a la existencia de múltiples competidores en la elaboración de las normas —Unión Europea, Comunidades Autónomascómo al desarrollo del Estado Social y la necesidad de leyes que no siempre cumplen ese ideal abstracto, no sirven para explicar el fin del Parlamento legislador. Sobre todo, teniendo en cuenta que el protagonismo acaba recayendo en el Gobierno de la Nación. De hecho, podemos afirmar que «un uso desmesurado del decreto-ley provoca una merma sustancial de la calidad democrática del sistema político al priorizar la lógica de la mayoría gubernamental en detrimento de la dialéctica pluralista que caracteriza la dinámica parlamentaria» ${ }^{31}$.

Dada las limitaciones formales del Decreto-ley que, recordemos, «no podrán afectar al ordenamiento de las instituciones básicas del Estado, a los derechos, deberes y libertades de los ciudadanos regulados en el Título I, al régimen de las Comunidades Autónomas ni al Derecho electoral general», la pregunta que cabe hacerse es si esto supone que el ordenamiento jurídico se ha estancado porque no hay posibilidades de modificarlo en tan importantes ámbitos, o se ha renunciado a ello, o, por el contrario, el Gobierno utiliza el Decreto-ley para modificar aspectos puntuales de leyes que requerirían una norma parlamentaria, arriesgándose a una eventual declaración de inconstitucionalidad que no se produciría hasta pasados unos años. Recordemos como en orden a las materias que podían ser objeto de Decreto-Ley, el Tribunal Constitucional, en una actitud de autocontención, ha considerado que lo que queda prohibido es la aprobación de regulaciones generales, así como aquellas otras de índole restrictiva $^{32}$. A pesar de esta actitud del máximo intérprete constitucional, no podemos obviar que el Decreto-ley tiene importantes límites materiales.

Pero lo cierto es que lo sucedido en nuestra historia reciente, en la que el Decreto-ley ha ido ganando peso de manera paulatina, tiene más que ver a mi juicio con la cómoda experiencia de los primeros 30 años, en los que el gobierno y su mayoría parlamentaria constituían un todo homogéneo, compacto, que tenía en frente a una minoría parlamentaria bien definida. En los últimos tiempos, con la entrada de nuevos partidos y los distintos frentes abiertos, las fronteras se han diluido y el sistema responde más a la lógica propia del parlamentarismo en la que el Gobierno tiene que recabar continuamente el apoyo del Parlamento. Por más que pueda haber correspondencias entre el Ejecutivo y su mayoría, y necesariamente tiene que haberla tras la investidura, la presencia de nuevas fuerzas en el arco parlamentario complica en ocasiones esa asimilación casi automática que se ha venido haciendo durante años, de manera que en los últimos tiempos, la mayoría de investidura no se corresponde

31 Carmona Contreras, A.M., «Decretos-Leyes: el medio y los fines», Agenda Pública, 8 de marzo de 2019.

32 Ibidem. 
necesariamente con la mayoría de gobierno. En este escenario, parece más fácil negociar una eventual mayoría para convalidar un Decreto-ley que proceder a la tramitación de una ley parlamentaria en la que, se pueden armar mayorías coyunturales para aprobar cuestiones no queridas por el Gobierno. Parece que los objetivos no pasan por regular materias reservadas a la ley, a la ley parlamentaria. Puede que el coste de negociar grandes reformas, que requerirían acuerdos amplios, sea demasiado.

$\mathrm{O}$ al menos eso es lo que se desprende a la vista de lo sucedido en los años 2016 a 2019, ambos inclusive. Es cierto, como ya se ha destacado, que durante este tiempo asistimos a dos investiduras fallidas con lo que eso supone de tiempo de un gobierno en funciones y unas Cámaras que primero, no funcionan a pleno rendimiento a pesar de estar recién constituidas dado que la regla general es la parálisis hasta tanto se produce la investidura ${ }^{33}$ y, segundo, transcurre un tiempo considerable entre la disolución y la constitución de las nuevas Cámaras. Aun así, más que justificar esta ausencia de proyectos legislativos por parte del Parlamento, esta situación no viene más que a confirmar nuestra tesis: la falta de centralidad del legislativo en estos últimos años.

En 2016, por ejemplo, únicamente se aprueban dos leyes orgánicas —realmente, dos reformas de sendas leyes orgánicas, la de Estabilidad Presupuestaria ${ }^{34}$ y la de Régimen Electoral General, para modificar algunas disposiciones en caso de repetición electoral de darse el supuesto del 99.5 CE — falta de acuerdo para la investidu$\mathrm{ra}^{35}$ - Este año no se aprobaron leyes ordinarias y sí siete Decretos-ley.

En 2017 se aprueba una única ley orgánica de modificación de la Ley del Jurado para permitir la participación de personas con discapacidad ${ }^{36}$, doce leyes ordinarias y 21 Decretos-Ley. En 2017 no hubo elecciones por lo que la actividad legislativa debería haber estado más equilibrada.

2018 se salda con la aprobación de 5 leyes orgánicas, 11 leyes ordinarias y 28 Decretos-ley. 2019 es aún peor: 3 leyes orgánicas, 5 leyes ordinarias y 18 Decretos-ley.

Más allá del número y proporción de leyes parlamentarias aprobadas, conviene detenerse un momento en lo que supone para un Estado el que el órgano central representante de la ciudadanía no ejerza su tarea legislativa con normalidad. La construcción de nuestro sistema de fuentes otorga a la ley parlamentaria una posición fundamental en el sistema de fuentes, atribuyéndole la regulación de las materias más importantes, ya sea a través de ley ordinaria o de ley orgánica. El Decreto-Ley, pensado para casos excepcionales, de «extraordinaria y urgente necesidad» no es una

33 Hemos tratado este punto en «Las limitaciones del Parlamento recién constituido durante la prorrogatio gubernamental», Revista de Derecho Político, 96, 2016.

34 Ley Orgánica 1/2016, de 31 de octubre, de reforma de la Ley Orgánica 2/2012, de 27 de abril, de Estabilidad Presupuestaria y Sostenibilidad Financiera.

35 Ley Orgánica 2/2016, de 31 de octubre, de modificación de la Ley Orgánica 5/1985, de 19 de junio, del Régimen Electoral General, para el supuesto de convocatoria automática de elecciones en virtud de lo dispuesto en el apartado 5 del artículo 99 de la Constitución.

36 Ley Orgánica 1/2017, de 13 de diciembre, de modificación de la Ley Orgánica 5/1995, de 22 de mayo, del Tribunal del Jurado, para garantizar la participación de las personas con discapacidad sin exclusiones.

(C) UNED. Revista de Derecho Politico

N. ${ }^{\circ} 111$, mayo-agosto 2021, págs. 109-136 
norma apta para actualizar la voluntad constituyente con normalidad. De hecho, la concepción del constituyente era muy otra: atribuir al Gobierno la posibilidad de elaborar, con carácter provisional, una norma capaz de dar respuesta a situaciones que requerían cierta agilidad, dejando para después, la participación del auténtico depositario de la potestad legislativa.

Pero el recurso exagerado al Decreto-ley no constituye la única causa de la pérdida de la centralidad del Parlamento como legislador, sino que cómo mucho explica el papel protagonista del Gobierno en la elaboración de normas con rango de ley y la falta de aprobación de leyes provenientes de proyectos de ley del gobierno. Existe otro elemento que ha contribuido y mucho a ello: el uso, o mejor dicho, el abuso, de la facultad de veto gubernamental de las proposiciones de ley que impliquen aumento de gasto o disminución de ingresos. Hemos tratado esta cuestión con profundidad en otro lugar pero conviene detenerse un momento ${ }^{37}$.

Ciertamente, a pesar de lo polémico que ha resultado la extensión de esta facultad a la elaboración en sí del mismo Presupuesto, con las dudas que ello plantea, nos interesa ahora la facultad de veto del Gobierno a la iniciativa legislativa que pueda alterar el Presupuesto en vigor por suponer más gastos o menos ingresos de los presupuestados. Y más que el uso o abuso que haya hecho el Gobierno, en este caso el de Mariano Rajoy, que opuso más de cuarenta vetos durante su mandato en la XII Legislatura, antes de la moción de censura que llevó a Pedro Sánchez al gobierno. En dos ocasiones, el veto gubernamental fue contestado por la Mesa del Congreso, que lo obvió incluyendo la tramitación de sendas iniciativas legislativas en el orden del día. El Gobierno por su parte respondió planteando sendos conflictos entre órganos constitucionales, resueltos por las SSTC 34/2018, de 12 de abril y 44/2018, de 26 de abril. El Tribunal Constitucional es taxativo a la hora de resolver la cuestión, poniendo fin a las extralimitaciones del Gobierno ${ }^{38}$.

La conflictividad que provocó esta cuestión tiene un marcado interés constitucional, además de político, dado que por un lado pone en duda elementos relevantes del veto y que hasta la fecha no habían planteado problemas: la afectación al ejercicio presupuestario en caso de prórroga de las cuentas del Estado y lo que es más grave, la

37 Gómez Corona, E., «Las potestades financieras de las Cortes Generales: del uso al abuso del veto presupuestario sobre las enmiendas con repercusiones financieras», Revista General de Derecho Constitucional, 28, 2018.

38 «El artículo 134.6 CE contiene una prerrogativa del Ejecutivo que tiene, como presupuesto habilitante, la vinculación estricta a la norma presupuestaria, que debe por ello verse afectada. Teniendo en cuenta, como ya se ha señalado, que cualquier iniciativa o proposición de ley es susceptible de suponer un incremento de gasto o una disminución de ingresos, el Gobierno debe justificar de forma explícita la adecuada conexión entre la medida que se propone y los ingresos y gastos presupuestarios. Esta conexión debe ser directa e inmediata, actual, por tanto, y no meramente hipotética. Debe además referirse al presupuesto en particular, sin que pueda aceptarse un veto del Ejecutivo a proposiciones que, en el futuro, pudieran afectar a los ingresos y gastos públicos, pues ello supondría un ensanchamiento de la potestad de veto incompatible con el protagonismo que en materia legislativa otorga a las Cámaras la propia Constitución (art. 66 CE)». STC 34/2018, de 12 de abril, F.J. Noveno. 
posibilidad de oponer el veto cuando la norma afecte a un futuro ejercicio presupuestario, recurriendo a dos argumentos: a que el artículo 134.6 CE no recoge de manera explícita que la afectación a los gastos e ingresos presupuestarios se refiere al ejercicio presupuestario en curso y, en segundo lugar, amparándose en el principio de estabilidad presupuestaria del artículo $135 \mathrm{CE}$, que se considera como un límite adicional a la potestad legislativa de las Cámaras.

Por otro lado, permite volver al polémico asunto del control sobre el veto, analizando si la Mesa de la Cámara puede o no levantarlo y bajo qué premisas, incidiendo en las relaciones entre el Gobierno y el Parlamento propias del sistema parlamentario de gobierno.

Como ya se ha apuntado, el veto gubernamental a las iniciativas legislativas con repercusión financiera, ya se trate de proposiciones de ley o enmiendas a proyectos de ley del gobierno, viene reconocido a nivel constitucional. Tiene sentido que una vez aprobadas las cuentas anuales, el Gobierno, como encargado de ejecutarlas, tenga que dar su consentimiento para que se produzca una alteración de las mismas. Se trataría así de cumplir con el principio de anualidad presupuestaria, además de resultar coherente con la atribución al Ejecutivo de la competencia de ejecución de los Presupuestos. Sin duda, constituye «una característica muy relevante del parlamentarismo racionalizado, mediante el cual se garantiza, una vez aprobado el Presupuesto por la Cámara, la dirección y ejecución del mismo, sin que el Parlamento pueda, sin la aquiescencia del Gobierno, modificarlo o desfigurarlo a lo largo de su vigencia anual» ${ }^{39}$.

Pero, su abuso por parte del gobierno no está justificado al margen de los supuestos para los que está previsto.

Es difícil saber qué motivos han pesado más en la falta de capacidad legislativa del Parlamento aunque sin duda, la cuestión del veto ha llegado a impedir la tramitación de casi cincuenta leyes, que una vez incluidas en el orden del día habrían obligado a un pronunciamiento por parte de las Cámaras. Precisamente eso, la tramitación de iniciativas que no se compartían, es lo que late detrás del veto gubernamental en el modo en el que se ha ejercido esta facultad constitucionalmente reconocida.

\section{La banalización del control de la acción del gobierno}

En una situación como la que se produce en el período que estamos estudiando, cabría pensar que el control de la acción de gobierno constituye uno de los ejes centrales de la actividad parlamentaria, permitiendo a las minorías presentes en las Cámaras cuestionar las políticas gubernamentales. Ciertamente, en un escenario en el que hay varios actores principales a ambos lados del espectro político, en los que las alianzas de gobierno no son estables y en el que hay muchos vectores de acuerdo y desacuerdo (derechos sociales, posición frente a Cataluña, Monarquía, distribución

39 Aragón Reyes, M. La organización institucional de las Comunidades Autónomas, Revista Española de Derecho Constitucional, 79, 2007, p. 24.

(C) UNED. Revista de Derecho Politico

N. ${ }^{\circ} 111$, mayo-agosto 2021, págs. 109-136 
territorial del poder), el Parlamento debería ser más dinámico que nunca, con múltiples iniciativas en las que los partidos mostrasen su postura en torno a los diversos temas y con alianzas coyunturales en función de las cuestiones a tratar.

Aunque no es este el lugar para analizar la necesidad de reformular esta importante tarea en la era de la comunicación, donde el control se realiza pensando más en las redes sociales que en el debate que se pueda suscitar en las Cámaras, lo cierto es que llama la atención la pérdida de relevancia de los instrumentos de fiscalización del Ejecutivo. Podría escribirse mucho sobre la efectividad de esta función en un mundo en el que la opinión pública, principal destinataria de la tarea de control de la oposición, se informa por múltiples canales y vías. A pesar de esto, la función de control de la acción del gobierno no sólo mantiene su importancia, sino que ante la pérdida de operatividad del Parlamento en otras facetas, como la legislativa y la presupuestaria, debería cobrar más valor que nunca. Sobre todo en el caso de gobiernos que no cuentan con el respaldo de la mayoría absoluta de la Cámara, por lo que cabría pensar en un escenario en el que las Cortes intensificaran su labor de fiscalización.

Sin embargo, una mirada atenta a nuestra vida política demuestra cómo la esencia del control parlamentario, el ofrecer al electorado un proyecto político alternativo con la esperanza de ganar su confianza en la próxima cita electoral, ha perdido la efectividad que pudo tener en los momentos posteriores a la Transición y en la era del bipartidismo. Ahora, los actores políticos se han multiplicado y además tienen muchas vías de difusión para sus proyectos, por lo que el impacto del control parlamentario es menor.

Ello provoca una banalización de la función de control, como otro síntoma más de la pérdida de centralidad del Parlamento. La responsabilidad, o parte de ella, habría que buscarla en los órganos de dirección del Parlamento, que se eligen en la sesión constitutiva y que en nuestro sistema no se han caracterizado precisamente por cumplir sus funciones de manera que respondan a los intereses de la Cámara en su conjunto. Todo lo contrario. De hecho, a ellos cabe atribuir la responsabilidad por despropósitos que han llegado hasta el Tribunal Constitucional, como el freno a toda iniciativa de control llevada a cabo tras la celebración de elecciones y antes de la investidura de la presidencia del Gobierno ${ }^{40}$.

Ciertamente, los largos períodos de inactividad que se han sucedido en las Cortes, en el ínterin que media entre la constitución de las Cámaras y la investidura de la presidencia, cuando se ha producido, han contribuido enormemente a esta situación de desparlamentarización de la vida política española. La idea que está en la base del sistema parlamentario de gobierno, que es la relación de fiducia entre Parlamento y Gobierno no se da tras las elecciones generales y antes de la investidura. Ahora bien, presuponer como consecuencia de ello, que durante ese tiempo las Cámaras recién constituidas no tienen nada que decir ni hacer sobre la actividad del Ejecutivo en

40 Sobre este particular puede consultarse Gómez Corona, E., «Las limitaciones del Gobierno recién constituido durante la prorrogatio gubernamental», Revista de Derecho Político, 96, 2016. 
funciones, es demasiado. De hecho, el órgano de representación popular, aunque ve limitadas muchas de sus atribuciones que necesitan del concurso de un Gobierno en plenitud de funciones, como la presupuestaria, no puede quedar maniatado a la hora de ejercer las funciones de control e incluso de impulso político. Así lo ha avalado el Tribunal Constitucional señalando cómo «siendo la función de control una función poliédrica, dirigida solo en último término a la ruptura de la relación de confianza entre el Congreso de los Diputados y el Gobierno, no cabe descartar la utilización de algunos de los instrumentos a los que nos hemos referido para el ejercicio de la función de control de la acción del Gobierno que corresponde a las Cortes Generales (art. 66.2 $\mathrm{CE}$ ), aunque el Gobierno esté en funciones (art. 101.2 CE), si bien con matices o limitadamente $(\ldots ..) »^{41}$.

De esta forma, el papel que juegan la Presidencia y la Mesa en el discurrir ordinario de la vida de las Cámaras es fundamental y su responsabilidad en la pérdida de centralidad del Parlamento, enorme. La Mesa es utilizada como una barrera para impedir el debate de asuntos que al Ejecutivo no le interesan, obstaculizando la función de control de la acción de gobierno.

Llama la atención en este contexto que la única moción de censura que ha prosperado entre nosotros se haya producido precisamente en este período. La moción de censura presentada por 84 diputados socialistas contra el Gobierno de Mariano Rajoy se saldó con la investidura de Pedro Sánchez el 1 de junio de 2018. Entre los motivos esgrimidos para plantearla, la sentencia del caso Gürtel, que vinculaba al partido de gobierno, el Partido Popular con graves casos de corrupción y que contribuyeron a que la mayoría absoluta del Congreso la apoyara.

Como es sabido, el presidente Pedro Sánchez disolvió las Cámaras y el 28 de abril de 2019 se celebraron elecciones generales que dieron lugar a una brevísima legislatura que terminaría sin acuerdo para la investidura. Únicamente tras las elecciones del 20 Noviembre de 2019 pudo Pedro Sánchez iniciar una legislatura, la primera con un gobierno de coalición, que pronto iba a verse truncada por la crisis del coronavirus.

\section{Una misión casi imposible: la designación parlamentaria}

La renovación de los órganos constitucionales que dependen de las Cortes Generales se había venido haciendo con cierta normalidad en base a un sistema de cuotas con arreglo al cual los dos grandes partidos, Socialista y Popular, se repartían los nombramientos en función de su fuerza numérica en las Cámaras. Aunque se habían planteado problemas en ocasiones, sobre todo en lo relativo a la elección de miembros del Tribunal Constitucional y del Consejo General del Poder Judicial, por lo general el acuerdo se alcanzaba.

Los cambios en la composición de nuestras Cámaras en el período analizado, necesariamente tienen su reflejo en esta competencia parlamentaria, que requiere de

41 STC 124/2018, de 14 de noviembre, F.J. Séptimo.

(C) UNED. Revista de Derecho Politico

N. ${ }^{\circ} 111$, mayo-agosto 2021, págs. 109-136 
mayorías muy cualificadas e involucra a una gran cantidad de fuerzas, con intereses muy diversos.

Sin duda, la situación más preocupante es la del Consejo General del Poder Judicial, órgano de gobierno del Poder Judicial y que desempeña importantes funciones en orden a la designación de magistrados y magistradas de los principales órganos judiciales del país. El actual Consejo cumplió su mandato a finales de 2018 y desde entonces no ha sido posible un acuerdo para su renovación ${ }^{42}$, que sigue enquistada mucho tiempo después.

En el caso del Tribunal Constitucional, en noviembre de 2019 cumplieron su mandato los cuatro magistrados designados por el Congreso de los Diputados, que tendría que proceder a la elección de cuatro nuevos miembros por una mayoría de 3/5.

El Consejo de Administración de Radio Televisión Española es un caso paradigmático de los efectos del vaciamiento de competencias del Parlamento. Ahora mismo, el ente público carece de consejo de administración debido a la falta de acuerdo político para designar a los consejeros. La corporación pública está gobernada, por primera vez y de forma interina, por una administradora provisional única elegida por el Congreso, Rosa María Mateo, que ha puesto su cargo a disposición del presidente del Gobierno. El último Consejo cesó en verano de 2018 y sus doce miembros tienen que ser elegidos por las Cortes Generales (seis por el Congreso y seis por el Senado), por mayoría de dos tercios. Hacen falta muchos votos, de muchos partidos distintos para proceder a una renovación que no llega.

En lo que respecta al Defensor del Pueblo y al Tribunal de Cuentas, los mandatos no concluyeron en el período analizado. En lo que respecta a los consejeros de este último, su mandato termina en los próximos meses y dadas las mayorías necesarias, 3/5 de Congreso y 3/5 del Senado para elegir cada Cámara a seis consejeros, el acuerdo no se augura nada fácil.

El Defensor del Pueblo tiene mandato hasta 2022. Veremos entonces.

42 A finales de 2018, el PSOE y el PP llegaron a un acuerdo para su renovación, con el conservador Manuel Marchena al frente del organismo. Pero unos polémicos mensajes que salieron a la luz del portavoz del PP en el Senado, Ignacio Cosidó, provocaron la renuncia de Marchena y dio al traste con el plan. Después, la interinidad del Ejecutivo y las Cortes prolongada durante todo 2019 por la doble cita electoral impidió cualquier posibilidad de retomar el asunto. Y ahora, el PP ha retirado su apoyo a aquel pacto dentro de una estrategia general de bloqueo a cualquier acuerdo con el Gobierno; además, la situación interina mantiene una mayoría conservadora que conviene, en general, a su partido. Así, como la renovación del consejo exige el respaldo de tres quintos de las Cámaras, el anunciado rechazo del PP y de Vox haría imposible de momento esa renovación. 


\section{A MODO DE REFLEXIÓN. LA DESPARLAMENTARIZACIÓN DEL SISTEMA POLÍTICO ESPAÑOL}

Que el sistema parlamentario de gobierno otorga la centralidad al Parlamento como órgano de representación directa de la ciudadanía es algo más que sabido. También lo es, que desde un punto de vista político esa centralidad recae en el Ejecutivo que tiene atribuida la dirección de la política interior y exterior, en un sentido amplio. Pero el Parlamento es el órgano por el que forzosamente tienen que pasar las decisiones más importantes para convertir la voluntad política del Ejecutivo en hechos; sus decisiones, en Derecho.

Que nuestro sistema de partidos, fuertemente jerarquizado, coloca al grupo parlamentario mayoritario en una posición subalterna del gobierno al que sustenta, no es ninguna novedad. Que eso en la práctica supone que el eje parlamento-gobierno se articula en torno a la mayoría de gobierno y su mayoría parlamentaria-minorías tampoco.

Lo que no cabía predecir, a mi juicio, es la falta de relevancia del Parlamento hasta para cumplir con sus cometidos constitucionales más esenciales, como la investidura de la presidencia del gobierno. Hemos comprobado las dificultades para armar mayorías en el Congreso, hasta el punto de que se han sucedido dos repeticiones electorales en tan sólo cuatro años. Y que los partidos mayoritarios no siempre hacen todo lo posible por evitar esa situación. Así, hemos visto a candidatos que renunciaban a presentarse a la investidura, como hizo Mariano Rajoy o que dejaban pasar el plazo previsto en el artículo 99.5 CE lánguidamente, sin apenas nuevos intentos, esperando quizá que la ciudadanía votara mejor en la siguiente cita electoral. Mejor, en función de sus intereses partidistas, claro.

Asimismo, el recurso al Decreto-ley como forma habitual de actualización de la voluntad constituyente, sumado a la inactividad del Parlamento legislador provoca la falta de actualización necesaria del ordenamiento jurídico, que corre un riesgo serio de no adaptarse a la realidad que tiene que normar. Es cierto que el Derecho suele ir por detrás de la sociedad, que avanza a un ritmo más rápido, pero el ordenamiento jurídico necesariamente tiene que adaptarse a las nuevas realidades. Un ordenamiento jurídico que no se actualiza conforme la sociedad lo va necesitando es un ordenamiento condenado a perder su vigencia por falta de aplicación. Cuando eso sucede, los riesgos de inoperatividad de ese Derecho son muchos. Y esos riesgos lo son para el Estado de Derecho que sustenta nuestro edificio constitucional.

Pero si relevancia tiene la dificultad para investir a la presidencia del Gobierno o para aprobar leyes, qué decir de la potestad presupuestaria que, no lo olvidemos, es la primera función que se atribuyó a los Parlamentos. Es muy difícil acometer cambios estructurales en una sociedad que encadena dos crisis seguidas, sin aprobar cuentas propias, abordando sólo gastos corrientes y sin poder incrementar la inversión en cuestiones que se consideren claves para el ejecutivo de turno. 
¿Cómo hemos llegado hasta aquí? ¿Qué ha pasado para que un sistema parlamentario racionalizado — quizá en exceso — pensado para fortalecer y dar estabilidad al Ejecutivo haya acabado provocando como efecto secundario la desparlamentarización del sistema? Seguramente los factores sean muchos y variados aunque creo que cobra una relevancia fundamental la actitud de parte de nuestra clase dirigente, que ha ido vaciando de competencias al Parlamento como órgano de representación de la soberanía popular, a base de soslayar su criterio siempre que ha sido posible. Las actitudes mostradas en los procesos de investidura por una parte, en los que se da por sentado el papel de mero actor del Parlamento para escenificar acuerdos adoptados fuera; el práctico abandono de la ley parlamentaria como instrumento para actualizar la voluntad constituyente; el recurso a cuentas prorrogadas en los últimos años y la banalización de la función de control parlamentario, esencial en un sistema en el que, recordemos, es el Parlamento el que sustenta al gobierno, así parecen evidenciarlo.

$\mathrm{Y}$ a todo este escenario se suma la pandemia del coronavirus que no sólo ha puesto en jaque nuestro modo de vida, sino que además, está sirviendo para poner a prueba la calidad de nuestros servicios públicos y la propia resistencia democrática de nuestras instituciones. Algunos Parlamentos, como el andaluz, han cerrado sin pudor considerando que a falta de previsión estatutaria y reglamentaria, cómo la iba a haber por otro lado, una Resolución de la presidencia podía ser suficiente para convocar la Diputación Permanente en pleno estado de alarma.

La actividad del Congreso de los Diputados tampoco ha sido la que cabría esperar en un momento en el que el Gobierno disfruta de los poderes extraordinarios que le concede la declaración de un estado excepcional. Lo más grave, es que la ciudadanía no ha notado mucho esa falta de labor parlamentaria, acostumbrada como estaba ya a la desparlamentarización de nuestro sistema político. Pero ese es otro debate y será abordado en otro trabajo.

Title

The de-parlamentarisation of the Spanish Political System. From an excessively rationalized parliamentarism to a «diluted» Parliament.

\section{Summary}

I. INTRODUCTION. II. THE POSITION OF THE «CORTES GENERALES» WITHIN THE SPANISH PARLIAMENTARY SYSTEM. A BRIEF NOTE ON AN EXCESSIVELY RATIONALISED MODEL. III. PARLIAMENTARY ACTIVITY IN THE 2011-2015 PERIOD: A 
«DILUTED »PARLIAMENT.1. The investiture of the presidency of the government as the first parliamentary mission. 2. The end of the principle of the annual nature of the budget. 3. A Parliament that does not legislate. 4. The trivialization of monitoring Government action. 5. An almost impossible mission: the parliamentary appointment. IV. FINAL REFLECTION. THE DE-PARLIAMENTARISATION OF THE SPANISH POLITICAL SYSTEM.

\title{
Resumen
}

Pocos podían vaticinar que la crisis que se inició en 2007 y que daría lugar al movimiento del $15 \mathrm{M}$ en 2011 y a la aparición de partidos de nuevo cuño, además de poner a prueba el bipartidismo imperante en España, iba a provocar una situación de inestabilidad política como la producida a partir de las elecciones de diciembre de 2015. Desde entonces han sucedido cosas inéditas en nuestra reciente historia constitucional: dos disoluciones anticipadas por falta de acuerdo para investir a un Presidente del gobierno; candidatos que renuncian a someterse a la investidura, como fue el caso de Mariano Rajoy o, candidatos que tras la primera votación fallida, no se someten a una segunda, probablemente por el miedo a salir investidos cuando preferían segundas elecciones.

También hemos asistido a la paradoja de cinco presupuestos aprobados en una misma legislatura y a la prórroga de varios de ellos. Una moción de censura que ha prosperado por primera vez, un uso inimaginable del veto gubernamental a las iniciativas legislativas con repercusiones presupuestarias y el uso de los escaños para impedir la renovación de órganos constitucionales fundamentales. Aunque esto último no es tan nuevo.

En las páginas que siguen vamos a analizar el efecto que todo esto ha provocado en la posición y funciones del Parlamento, órgano central de nuestro sistema constitucional, dado su carácter de único órgano legitimado democráticamente de manera directa. Nos vamos a centrar en el período que abarca desde finales de 2015 hasta diciembre de 2019, en las Legislaturas XI, XII y XIII.

\begin{abstract}
Spain's 2007 political crisis gave birth to the M-15 movement and the emergence of new parties in 2011. Few could have predicted that such a crisis would not only test the so-far prevailing two-party system, but it would also lead to a situation of severe political instability during the December 2015 elections. Since then, several unprecedented events have occurred in our recent constitutional history, namely: two anticipated dissolutions of the Parliament due to the lack of agreement to elect a President of the government; candidates who renounced to undergo the investiture procedure, as it was the case of Mariano Rajoy; or, candidates who, after the first vote failed, did not follow up to a second one,
\end{abstract}


probably because of fear of being invested when they rather preferred second elections.

We have also witnessed the paradox of five national budgets approved in the same term and the extension of several of them: a motion of censure that has prospered for the first time, an unimaginable use of the government's veto on legislative initiatives with budgetary implications, and the use of Parliamentary seats to prevent the renewal of fundamental constitutional bodies. Tthe latter, however, is not so new.

In the pages that follow, we will analyze the effect that all these events have had on the position and functions of the Parliament, the central organ of our constitutional system, given its character as the only directly democratically legitimised organ. We will focus on the period from the end of 2015 to December 2019, comprising the 11th and 12th Legislatures.

\section{Palabras clave}

Sistema parlamentario de gobierno; funciones parlamentarias; Cortes Generales; Gobierno.

\section{Key words}

Parliamentary system of government; parliamentary functions; Spanish Parliament; Government. 